\title{
As frágeis fronteiras da institucionalização dos campos do saber
}

\author{
Diogo da Silva Roiz ${ }^{1}$ \\ Universidade Estadual de Mato Groso do Sul
}

LIMA, L.C. História, ficção, literatura. São Paulo: Companhia das Letras, 2006.

Todo começo é difícil em qualquer ciência

(MARX, 2008; p. 15).

To prefácio a primeira edição, do livro 1, d'O Capital, lançada em 1867, 1 Karl Marx, no intento de explicar suas intenções com a obra, demarcaria as dificuldades quanto à sistematização de um campo do saber, na medida em que fosse tomado como uma Ciência - dificuldade, aliás, agravada na medida em que este campo esteja em seu processo inicial de consolidação teórica e metodológica. A sua preocupação não era fortuita, devia-se as próprias características de sua época, em procurar a todo custo, criar devidamente as fronteiras de cada campo do saber, em função do processo de institucionalização para o qual cada área estava então caminhando. Tendo as suas bases nos séculos 17 e 18, com o "racionalismo clássico" e o "movimento iluminista", o século 19 será marcado por uma tentativa sistemática de se encontrar padrões adequados para se definir cientificamente cada campo do saber, de acordo com procedimentos e técnicas adequadas à comprovação experimental e a manipulação científica dos dados. Convergindo com as características gerais daquele momento, no campo das (chamadas) "Ciências Humanas" não foi diferente, já que tiveram que seguir aos padrões consolidados, ou em processo de consolidação, das "Ciências Exatas" (e, em menor proporção, das "Biológicas"). Muito embora, as "marcas" desse processo pairassem sobre todas as áreas, para àquelas cujas 'origens' (milenares) as diferenciavam, sobre proporções variadas, dos "novos" campos do saber que se desenvolviam no interior daquele processo histórico geral, o "preço" a ser pago foi ainda maior. Na medida em que, em longo prazo, o processo de sua institucionalização resultou na permanência de fragilidades teóricas nas fronteiras estabelecidas entre cada uma delas, ao serem demarcadas as suas especificidades. No caso da História e da Literatura, em pleno século 21, estas questões continuam sendo cruciais, por que desde suas origens essas questões circunstanciam seus itinerários.

${ }^{1}$ Doutorando em História pela UFPR, bolsista do CNPq. Mestre em História pela UNESP. Professor da UEMS (diogosr@yahoo.com.br). 


\section{UMANAS}

Em seu livro (História. Ficção. Literatura), Luiz Costa Lima procurou rever essas questões, e, em muitos pontos, de forma inovadora. Contudo, vale destacar desde o início duas dificuldades, que não apenas esse livro, mas quase toda a obra do autor impõe: a) primeiro, o convite a um conhecimento apurado dos clássicos da História, da Filosofia e da Literatura, por que torna necessária a consulta (senão completa, ao menos parcial) de várias passagens que o autor discute ao longo da obra, supondo que o leitor o esteja acompanhando adequadamente, com as referências dos textos analisados; b) segundo, nitidamente o autor articula cada um de seus livros, dando continuidade a discussões iniciadas em obras anteriores, prolongando raciocínios, ou ainda, avançando com outros argumentos, e, as vezes, até novas interpretações. Em ambos os casos, Luiz Costa Lima, de um modo muito positivo, exige um pouco de seu leitor. Mas o exige, em função da discussão efetuada, que paira sobre um tema "amplo" e "complexo". E é justamente sobre esse aspecto, que o autor define sua "paixão" como pesquisador, destacando que seu "interesse maior sempre esteve em compreender a temporalidade de um problema teórico, isto é, compreender de que modo era possível verificar a dinâmica das ideias, sem submetêlas ao esquema linear das histórias literárias nacionais" (2009,p. 14-5). Mais precisamente, essa abordagem se justificava também, segundo ele, pela dificuldade que o pesquisador brasileiro encontra em ter acesso à bibliografia completa de autores e obras estrangeiras, assim como a abordagem dedicada a certos temas.

Dito isto, seu principal objetivo com este livro foi demonstrar que desde que se originaram a Literatura, a História e a Ficção, seus respectivos esquemas verbais pairaram sobre um arcabouço teórico frágil, em meio ao qual se construiu diferenciações, entre cada uma delas, fixadas de modo mais detalhado, a partir do século 19, mas sem com isso se corrigir os problemas teóricos, que lhes foi herdado desde a Antiguidade Clássica e Tardia. Como resolver esse problema, ou ainda mais, repensar os caminhos que foram trilhados por cada uma delas, além de ser o ponto alto do livro, constituindo-se numa tarefa árdua e difícil, também permitiu, segundo o autor, que revisse mais detalhadamente as fragilidades teóricas que proporcionaram ainda formas inadequadas para que fossem diferenciados cada um daqueles campos do saber - fato, aliás, já ressaltado por Pedro Caldas (2006) em sua resenha do livro.

Donde a necessidade de se voltar criticamente às construções teóricas do passado, onde se forjariam os esquemas conceituais de cada uma daquelas áreas, inserindo-as ao mesmo tempo em campos específicos. Daí as idas e vindas do autor, entre os pensamentos e as argumentações de Homero, Heródoto, Tucídides, Cícero, Virgílio, Aristóteles, Santo Agostinho, Vico, Voltaire, Kant, para ficarmos apenas nos principais, além de uma correspondente comparação, 


\section{As frágeis fronteiras da institucionalização dos campos do saber}

e usos efetuados pelos autores contemporâneos sobre aqueles clássicos, como: François Hartog, Hayden White, Moses Finley, Arnaldo Momigliano, entre outros. Para ele, enquanto no "discurso ficcional" por não "postular uma verdade, mas a põe entre parênteses" se fixaria num de seus postulados básicos, na "historiografia" há "um projeto peculiar: desde Heródoto e, sobretudo, Tucídides, a escrita da história tem por aporia a verdade do que houve", por isso, torna-se "particularmente difícil ao historiador não considerar prova aporética o que resulta do uso de suas ferramentas operacionais" (p. 21). Desse modo, as "tentativas de Cornford e Hayden White de aproximá-la do poético procuraram conjurar essa dificuldade; terminaram, contudo, por criar um desvio tão grave quanto: converter a escrita da história em uma modalidade de ficção" (Idem). Apesar dos evidentes pontos de aproximação entre elas, como o "critério de seleção dos acontecimentos também se aplica(r) a uma obra ficcional" (p. 36), não há como deixar de lado o que as separam e as distinguem, mesmo ao abordarem questões ou fontes semelhantes. Além disso:

Se a história é menos envolvida pela mimeses do que o texto poético é porque... nela a imaginação é mera serva do entendimento. Mas, ao contrário do que sucede nas ciências da natureza, a sua é uma submissão incompleta. Submetida à parcialidade, a verdade que a escrita da história demanda é sempre porosa... sujeita à retificação, e não só à do erro de julgamento de seu agente. Mas isso não a torna constitutivamente imaginativa. Parcial, a verdade na escrita da história não reduplica o que já estivesse no fato, mas o submete a uma deliberação judicativa; a verdade é da mesma família do que sucede ao fim de um processo judiciário (p. 65).

Assim, desde o início, quando História e Literatura procuravam se constituir como gêneros específicos na Antiguidade Clássica e Tardia, formar-se-ia o seguinte paradoxo na escrita da história:

Tudo isso remetia à verdade, à verdade do sucedido. O princípio fundador da história é, ao mesmo tempo, o seu obstáculo. Desde seus primeiros praticantes, uma maneira de afastar o obstáculo consistiu em converter o princípio em aporia. Mas a única aporia indevassável é a da crença, que não se concilia com a própria revisão continuada requerida pela escrita da história. Já a aporia da história há de considerar que seu conteúdo, a verdade, 


\title{
HUMANAS
}

\begin{abstract}
é sempre incerto. A sempre incerta verdade é a meta do historiador. Incerta, ela tem uma face devassável, a leitura que se faça do que houve; e uma face indevassável, a escura verdade que não se esgota na nomeação dos fatos. Pode-se dizer que essa já não interessa ao ofício do historiador, preocupado em distinguir-se dos filósofos. Mas a nós, que pertencemos a outro tempo, ela importa (p. 104).
\end{abstract}

Ao retirarem da pura empiricidade dos fatos os ingredientes fundamentais de seu relato, é que "essa fonte comum, a radical diferença de seus resultados, e a falta comum de teorização suficiente de ambas, que dão lugar aos equívocos que têm acompanhado a escrita da história e a literatura" (p. 117). Por sua vez, "se a história é um discurso relativamente tardio, que, desde seu início, teve como aporia destacar as fontes confiáveis de captação do que houve, a poesia não começa a se entender a si mesma... a se pôr como questão, senão tardiamente, pelas palavras com que deuses e homens dizem como vêem as ações do herói-poeta, Ulisses", quer dizer, a "decadência" que a configuração da obra supõe e o reconhecimento de que sua linguagem implica uma camada de "graça" sob um fundo de pensamento explicitam a precariedade do estatuto teórico da poesia" (p. 175). Nesse aspecto, os "gêneros literários não estritamente ficcionais mais bem aparecem como modalidades oscilantes, muitas vezes auxiliares da história social, sem contudo aí se esgotarem" (p. 382).

Portanto, ao indagar as aproximações e distanciamentos conceituais e metodológicos entre História, Ficção e Literatura, o autor nos oferece uma releitura do itinerário historiográfico desses campos do saber, além de avançar sobre a interpretação de suas fragilidades teóricas, e propor uma reconstrução teórica e metodológica entre elas, sem com isso deixar de lado suas especificidades. Nesse sentido, a obra é uma referência e, não por acaso, recebeu o prêmio Jabuti na área em 2007 - o que só dá maior envergadura as suas qualidades. Por essas razões, o texto é um convite ao leitor, para ver com maior acuidade essas áreas, além de compreender melhor seus dilemas e seus paradoxos teóricos, conceituais e metodológicos.

\section{Referências bibliográficas}

CALDAS, P.S.P. A consciência híbrida: História. Ficção. Literatura, de Luiz Costa Lima. In. Fênix. Revista de História e Estudos Culturais, 3(3), 2006. 
LIMA, L.C. O controle do imaginário \& a afirmação do romance. Dom Quixote, as relações perigosas, Moll Flanders, Tristam Shandy. São Paulo: Companhia das Letras, 2009.

MARX, K. O capital. Crítica da economia política. Livro Primeiro: o processo de produção do capital. Volume 1. Tradução: Reginaldo Sant'Anna. 26 Edição. Rio de Janeiro: Civilização Brasileira, 2008. 